\title{
Investigation of Iron Complex Formation of Anti-Hypertensive Drug: Methyldopa
}

\author{
Tehmina Fiaz ${ }^{1}$, Nasreen Fatima1, S. Zafar Abbas Zaidi'1, Tanveer Abbas², Mohib R. Kazimi3 ${ }^{*}$ \\ ${ }^{1}$ Department of Chemistry, University of Karachi, Karachi, Pakistan \\ ${ }^{2}$ Department of Microbiology, University of Karachi, Karachi, Pakistan \\ ${ }^{3}$ Department of Applied Chemistry and Chemical Technology, University of Karachi, Karachi, Pakistan \\ Email: ${ }^{*}$ mrkazmi@uok.edu.pk
}

Received 7 April 2015; accepted 18 May 2015; published 20 May 2015

Copyright (C) 2015 by authors and Scientific Research Publishing Inc.

This work is licensed under the Creative Commons Attribution International License (CC BY).

http://creativecommons.org/licenses/by/4.0/

(c) $\underset{\mathrm{EY}}{\mathrm{B}}$ Open Access

\section{Abstract}

The drug administered for any disease may play an unwanted function in biological system. They may have multiple counter effects, one of which is their interaction to bioactive metals. Iron is most common bio essential metal and is reported to interact with antihypertensive drug methyldopa. In the present study, above said complex is analyzed by UV-Visible spectrophotometry. Formation constant of the complex is calculated by using mole ratio method and single point statistical method which is in the range of $\mathbf{1 0}^{10}$, values are also calculated which are independent of $\mathbf{p H}$ like formation constant. Absorbance maxima were found to be dependent on $\mathrm{pH}$. At lower $\mathrm{pH}$ complex shows two broad bands centered at $430 \mathrm{~nm}$ and $730 \mathrm{~nm}$. With the rise in pH later peak shifts toward lower wavelength, so $615 \mathrm{~nm}$ is selected for further studies. Molar extinction coefficient of the complex is explored by serial dilution method. At all wavelengths it increases with increase in $\mathrm{pH}$. Mole ratio and slope ratio methods are used for exploring stoichiometry. Metal to ligand combining ratio in the complex is $1: 2$ at $\mathrm{pH} 4.0$ and $\mathrm{pH} 4.5$ while $1: 3$ at pH 5.0 and $\mathrm{pH} 5.5$.

\section{Keywords}

Iron, Methyldopa, Stoichiometry, Formation Constant, UV-Spectrophotometery

\section{Introduction}

Iron, is one of the most abundant biological metal, existing in two oxidation states. In its lower oxidation state, it is more soluble and more biologically available. Iron supplements are among the most recurrently recommended medicines [1]. Patients are often treated with several drugs and some time they consume more than one phar-

\footnotetext{
${ }^{*}$ Corresponding author.
}

How to cite this paper: Fiaz, T., Fatima, N., Zaidi, S.Z.A., Abbas, T. and Kazimi, M.R. (2015) Investigation of Iron Complex Formation of Anti-Hypertensive Drug: Methyldopa. American Journal of Analytical Chemistry, 6, 551-558. 
maceuticals. When patients ingest two or more drugs simultaneously, there is a risk of drug-drug interaction [2]. As Iron has strong affinity toward Nitrogen and Oxygen donor ligand that is why variety of drugs can form chelates with Iron. Reduction in the absorption of many drugs like, penicillamine [2], levodopa [3], carbidopa, ciprofloxacin and methyldopa [3]-[7], is caused due to Iron. The major mechanism by which iron interacts with these drugs is the formation of iron-drug complexes [8]. Methyldopa (MD) is one of the catecholic molecules which are liable to interact with Iron. It is chemically known as 1-methyl-3, 4-dihydroxyphenylalanine, it is a catecholamine widely used anti-hypertensive drug with structure illustrated in Figure 1. The MD is a centrally acting alpha ${ }_{2}$-adrenoreceptor agonist, which reduces sympathetic symptoms and results in decrease in blood pressure [9].

Different analytical methods and techniques have been employed for the analysis of catechol derivatives in pharmaceuticals or in biological samples. These procedures include titrimetry, Fluorimetric determination, kinetic studies, amperometry, gas chromatography, high-performance liquid chromatography (HPLC), chemiluminescence and voltammetric analysis [10]-[24]. These methods are not simple and involve procedures with severe control of the experimental conditionsor otherwise are associated with expensive or delicate instruments. Stoichiometry and other spectral characteristics of Levodopa and other similar complexes have already been reported but still there is lack of data reporting formation constant of said complexes [25]-[28].

In the present study using a simple spectrophotometric technique Formation constant of the Methyldopa complex of Iron (II) is explored in the $\mathrm{pH}$ range of 4.0 to 5.5. Two different methods of calculation are used and results found are in agreement with each other, Stoichiometry of the complex is also reviewed by using Mole ratio and Slope ratio method.

\section{Experimental}

\subsection{Materials}

Analytical grade reagents were used throughout the study. $\mathrm{Fe}\left(\mathrm{NH}_{4}\right)_{2}\left(\mathrm{SO}_{4}\right)_{2} \cdot 6\left(\mathrm{H}_{2} \mathrm{O}\right)$ was obtained from Merck and Methyldopa was obtained from Wild Wind, $\mathrm{CO}_{2}$ free distilled deionized water was used for the preparation of buffer and complex solutions.

\subsection{Absorbance Maxima}

Absorbance maxima of the complex, was investigated by treating $0.5 \mathrm{mM}$ of $\mathrm{Fe}(\mathrm{II})$ solution with adequate excess of Methyldopa solution prepared in Acetate buffer of desired $\mathrm{pH}$. The $\mathrm{pH}$ of the complex was recorded by JENWAY370 pH meter and SCHIMADZU model number UV-160A was used for scanning complexes in visible region. Spectrum of the complex indicated presence of a broad peak centered at $615 \mathrm{~nm}$ and another peak at $430 \mathrm{~nm}$, shifting of the peak with rise in $\mathrm{pH}$ was also observed that is why wavelength of 615 nm was selected for further study as illustrated in Figure 2.

\subsection{Molar Extinction Coefficients and Serial Dilution}

Solutions of different dilutions were prepared in Acetate buffer of desired $\mathrm{pH}$. Absorbance was recorded for all diluted solutions at selected wavelengths i.e. $615 \mathrm{~nm}$. Table 1 demonstrates a plot of absorbance for different dilutions against metal concentration provided the slope for determining molarextinction coefficient [28].

\subsection{Mole Ratio}

Accurate amounts of Iron (II) salt was used to prepare stock solution of metal in deionized distilled water. Stock solution of Methyldopa was prepared in acetate buffer of required $\mathrm{pH}$. Different aliquots of ligand solution were<smiles>C[C@](N)(Cc1ccc(O)c(O)c1)C(=O)O</smiles> 


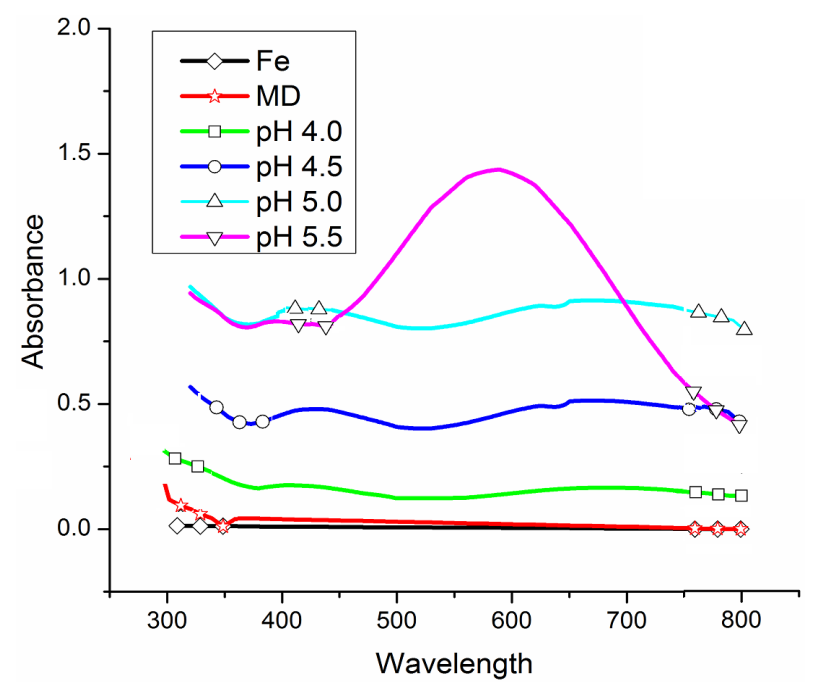

Figure 2. UV-VIS spectra of Fe(II)-MD complex at variable $\mathrm{pH}$.

Table 1. Molar absorptivity of Fe(II)-MD complex in different $\mathrm{pH} ;[\mathrm{Fe}(\mathrm{II})]=0.5 \mathrm{mM} ; \mathrm{T}=25^{\circ} \mathrm{C} \pm 1{ }^{\circ} \mathrm{C}$.

\begin{tabular}{cccc}
\hline \multicolumn{3}{c}{ Molar absorptivity of Fe (II)-MD complex } \\
\cline { 2 - 4 } $\mathbf{p H}$ & \multicolumn{3}{c}{ Wavelength } \\
\cline { 2 - 4 } & $\mathbf{4 3 0} \mathbf{~ n m}$ & $\mathbf{6 1 5} \mathbf{~ m m}$ & $\mathbf{7 3 0} \mathbf{~ n m}$ \\
\hline 4.0 & 1410 & 1126 & 1066 \\
4.5 & 2030 & 2016 & 1740 \\
5.0 & 2460 & 2848 & 1770 \\
5.5 & 2642 & 3498 & 1912 \\
\hline
\end{tabular}

added in $0.5 \mathrm{mM}$ metal solution in order to get various ligand metal ratios ranging from 0.5:1 to 9:1. The final volume was maintained with respective buffers in all cases. The absorbance was recorded at $615 \mathrm{~nm}$ and temperature maintained at $25^{\circ} \mathrm{C} \pm 1^{\circ} \mathrm{C}$ is illustrated in Figure 3 [29].

\subsection{Slope Ratio}

The slope ratio method was used to find the Stoichiometry of the complex. Two series of solutions were prepared. In first half constant volume of $0.5 \mathrm{mM}$ Fe(II) was treated with variable volumes of $5 \mathrm{mM}$ Methyldopa, where as in the other half of the analysis, MD was kept constant versus variable volumes of Fe(II) solution. Resulting complexes were scanned at selected wavelength of $615 \mathrm{~nm}$ and the recorded absorbance was plotted versus concentration of varying specie. Stoichiometry of the complex was interpreted by calculating ratio of slope of two straight lines [30]. Figure 4 is a plot of slope ratio at $\mathrm{pH}$ 5.5. The same method was used at $\mathrm{pH} 4.0$, 4.5 and 5.0. All experiments were performed in triplicate in order to get consistent results.

\section{Results and Discussion}

\subsection{Molar Extinction Coefficient}

The results show that Methyldopa-Fe have two distinct peaks at low pH, which appear at 430 and $730 \mathrm{~nm}$. The absorbance increases at these wavelengths with the rise of $\mathrm{pH}$. However, the peak at 730 shifts to lower wavelength, as $\mathrm{pH}$ is increased. The molar extinction coefficient values were evaluated by serial dilution of complex (standard curve method). The values found are indicated in Table 1 and are found to be very high, increasing with the $\mathrm{pH}$. The high value indicates charge transfer band either LMCT or MLCT. 


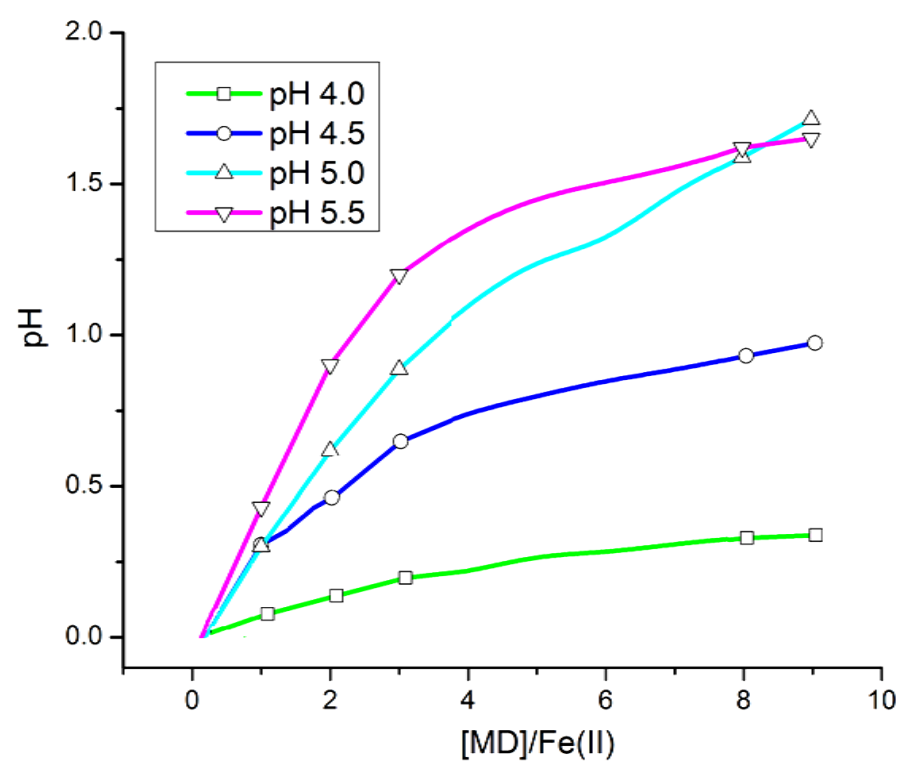

Figure 3. Stoichiometry of Fe(II)-MD complex by mole ratio method in Acetate bufferof variable $\mathrm{pH}$; $[\mathrm{Fe}(\mathrm{II})]=0.5 \mathrm{mM} ; \mathrm{T}=25^{\circ} \mathrm{C} \pm 1{ }^{\circ} \mathrm{C}$; Selected Wavelengh $=615 \mathrm{~nm}$.

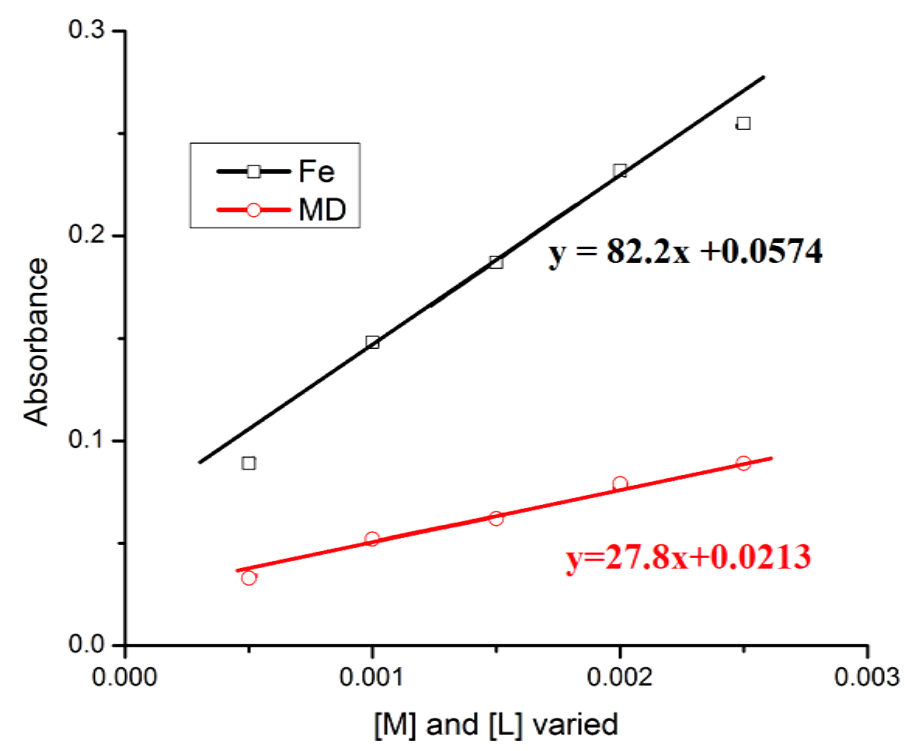

Figure 4. Plots of slope ratio method of Fe(II)-MD, in Acetate Buffer of $\mathrm{PH}$ 5.5; Absorbance vs. concentration of variable reagent, $\mathrm{T}=25^{\circ} \mathrm{C}$ $\pm 1^{\circ} \mathrm{C}$; Selected Wavelength $=615 \mathrm{~nm}$.

At all $\mathrm{pH}$, work was carried on three wavelengths, 430, 615 and 730, selected purposely. At $430 \mathrm{~nm}$ the $\varepsilon$ increases with $\mathrm{pH}$. Same trend is found at all wavelengths. Considering $\varepsilon$ on a single $\mathrm{pH}$, it is interesting to note that at $\mathrm{pH} 4.0$ and 4.5 , the highest value is found at $430 \mathrm{~nm}$, while at $\mathrm{pH} 5.0$ and $5.5, \varepsilon$ is higher at $615 \mathrm{~nm}$. This observation may correspond to the result, that, at low $\mathrm{pH}, 2 \mathrm{MD}$ molecules chelate iron (II), while with the rise of $\mathrm{pH}$, all six coordination sites of iron are occupied by MD, forming $\mathrm{Fe}(\mathrm{MD})_{3}$. as suggested in Figure 5.

\subsection{Stoichiometry}

Stoichiometry is evaluated by mole ratio and further confirmed by slope ratio method. It has been found that at low $\mathrm{pH} \mathrm{Fe}\left(\mathrm{H}_{2} \mathrm{O}\right)_{2}(\mathrm{MD})_{2}$ forms while it converts to $\mathrm{Fe}(\mathrm{MD})_{3}$ due to de-protonation of ligand at higher $\mathrm{pH}$ as 
showed in Table 2. Since the $\mathrm{pH}$ have a significant effect on complex formation, indicate that, the chelation of metal take place through catecholic side.

Results obtained by Slope ratio method are in good agreement.

\section{3. $\beta$ and Formation Constant Evaluation}

$\beta$ value of $\mathrm{ML}_{1}, \mathrm{ML}_{2}$ and $\mathrm{ML}_{3}$ species formed gradually in the solution of varying stoichiometric ratio were calculated by using moleratio data applying single point statistical method where $\beta$ is the ratio of complex concentration to the product of remaining concentration of metal and ligand at each data point. Overall formation constant of the complex was calculated by using same method; direct moleratiois also used to calculate $\mathrm{K}_{\mathrm{f}}$ in this method formation constant is ratio of equilibrium concentrations of products and reactants [30].

The overall formation constant for $\mathrm{Fe}(\mathrm{MD})_{3}$ is found very high about $10^{10}$. The values of $\mathrm{K}_{\mathrm{f}}$ remains unaffected by $\mathrm{pH}$ when determined in Table 3 and Table 4 at $615 \mathrm{~nm}$. Step wise formation constant at each $\mathrm{pH}$ is also similar i.e. no significant change is observed with $\mathrm{pH}$. $\mathrm{K}_{\mathrm{f}}$ obtained by the two methods graphical and statistical handling of mole ratio data is consistent.

\section{Conclusions}

Acidic $\mathrm{pH}$ was selected for study, No spectral evidence of complexation was observed at $\mathrm{pH}$ below 4 even in the

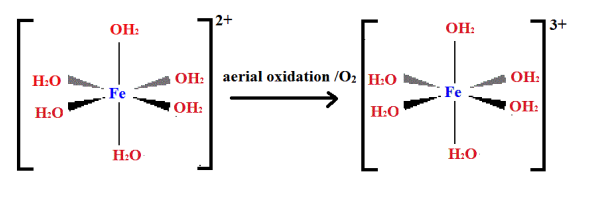

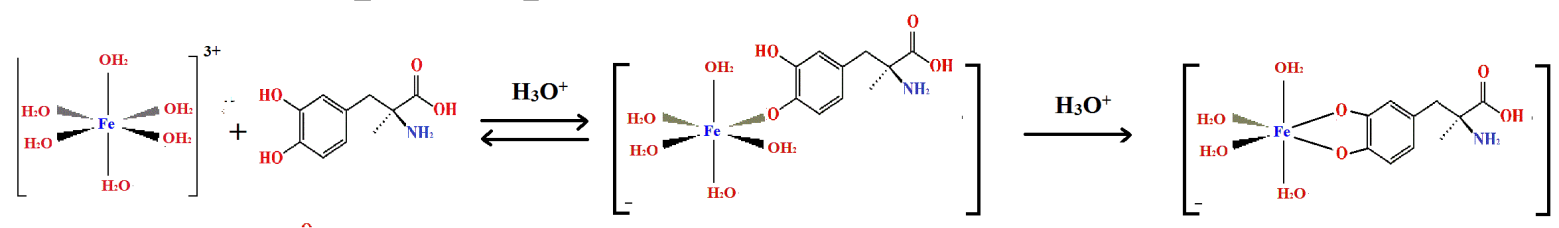

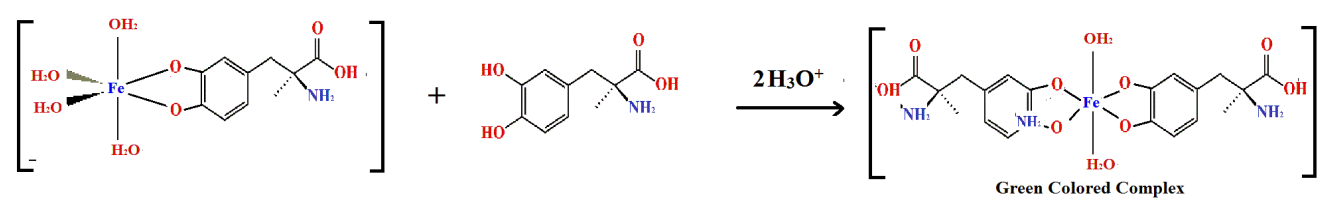

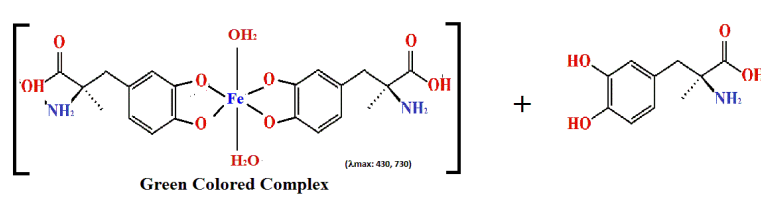

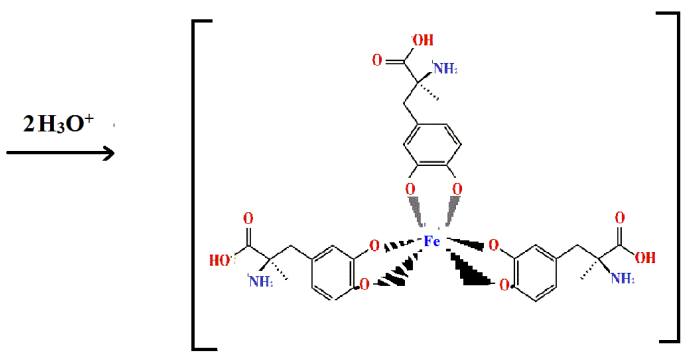

Figure 5. Suggested reaction mechanism between Methyldopa and iron.

Table 2. Stoichiometry of Fe(II)-MD Complex at $615 \mathrm{~nm}$ olar Absorptivity of Fe(II)-MD Complex in different pH; [Fe(II)] $=0.5 \mathrm{mM} ; \mathrm{T}=25^{\circ} \mathrm{C} \pm 1^{\circ} \mathrm{C}$.

\begin{tabular}{cccccc}
\hline & \multicolumn{5}{c}{ Stoichiometry } \\
\hline pH & $\mathbf{4 . 0}$ & $\mathbf{4 . 5}$ & $\mathbf{5 . 0}$ & $\mathbf{5 . 5}$ \\
\hline Sloperatio method & $2: 1$ & $2: 1$ & $3: 1$ & $3: 1$ \\
Moleratio method & $2: 1$ & $2: 1$ & $3: 1$ & $3: 1$ \\
\hline
\end{tabular}


Table 3. Overall formation constant $\mathrm{K}_{\mathrm{f}}$ of Fe(II)-MD Complex.

\begin{tabular}{ccccc}
\hline & \multicolumn{2}{c}{ Formation constant } & & \\
\hline $\mathbf{p H}$ & $\mathbf{4 . 0}$ & $\mathbf{4 . 5}$ & $\mathbf{5 . 0}$ & $\mathbf{5 . 5}$ \\
\hline Statistical method & $3.4 \mathrm{E}+05$ & $1.6 \mathrm{E}+06$ & $1.4 \mathrm{E}+09$ & $9.2 \mathrm{E}+09$ \\
Graphical method & $6.2 \mathrm{E}+05$ & $2.8 \mathrm{E}+06$ & $3.6 \mathrm{E}+09$ & $1.2 \mathrm{E}+11$ \\
\hline
\end{tabular}

Table 4. Stepwise formation constants of Fe(II)-MD Complex.

\begin{tabular}{ccccc}
\hline & \multicolumn{5}{c}{$\boldsymbol{\beta}$ values by statistical method } \\
\hline $\mathbf{p H}$ & $\mathbf{4 . 0}$ & $\mathbf{4 . 5}$ & $\mathbf{5 . 0}$ & $\mathbf{5 . 5}$ \\
\hline $\boldsymbol{\beta}_{1}$ & 2.57 & 3.34 & 2.83 & 3.38 \\
$\boldsymbol{\beta}_{2}$ & 5.54 & 6.23 & 5.98 & 6.15 \\
$\boldsymbol{\beta}_{3}$ & - & - & 9.16 & 9.2 \\
\hline
\end{tabular}

presence of catecholic ligand, which is otherwise reported to catalyze this oxidation [27]. This observation also supports that Iron is present in its higher oxidation state in investigated complex which is not possible at a very low $\mathrm{pH}$. Spectra and mole ratio curves showed formation of $\mathrm{ML}_{2}$ complex at 4.0 to $4.5 \mathrm{pH}$, while an evidence of $\mathrm{ML}_{3}$ type complexation was found at higher $\mathrm{pH}$. The shifting of peak also indicates variation in nature of complex. The results were verified by slope ratio method. Effect of $\mathrm{pH}$ shows that chelation depends on de-protonation of MD. It indicates that chelation is through catecholic moiety which has strong affinity for Iron (III). Therefore, the high values of $\varepsilon$ are indication of LMCT charge transfer bands, which is characteristic of catecholic ligands. These findings are consistent with the results of $\mathrm{Fe}^{2+/ 3+} \mathrm{LD}$ system [27].

The $\mathrm{K}_{\mathrm{f}}$ values of the complex was found very high, and remained constant regardless of $\mathrm{pH}$. The complex of iron formed with MD is very strong.

Strong complexation at $\mathrm{pH} 4.0$ and above while no complex formation up to $\mathrm{pH} 3.5$ reveals that this drug can effectively be taken orally as the $\mathrm{pH}$ of stomach (1 to 3.5) does not affect its availability in presence of Fe.

According to Campbell et al., iron supplements reduce the bioavailability of many drugs including methyldopa due to chelate formation, however no complexation observed at $\mathrm{pH}$ lower than 4.0, indicate that chelation and therefore reduction of bioavailability did not occur in stomach.

\section{Acknowledgements}

Authors are grateful to Dr. Muhammad Baqar Ali (MBBS) of Claims Med Inc. for fruitful discussion about methyldopa and iron supplements. He facilitated in concluding that this drug can effectively be taken orally as the $\mathrm{pH}$ of stomach does not affect its availability in presence of Feat $\mathrm{pH} 4.0$ up to $\mathrm{pH} 3.5$.

\section{References}

[1] La Piana Simonsen, L. (1989) Top 200 Drugs of 1988. Pharmacy Times, 40.

[2] Osman, M.A., Patel, R.B., Schuna, A., Sundstrom, W.R. and Welling, P.G. (1983) Reduction in Oral Penicillamine Absorption by Food, Antacid, and Ferrous Sulfate. Clinical Pharmacology and Therapeutics, 33, 465-470. http://dx.doi.org/10.1038/clpt.1983.63

[3] Campbell, N.R.C. and Hasinoff, B. (1989) Ferrous Sulfate Reduces Levodopa Bioavailability: Chelation as a Possible Mechanism. Clinical Pharmacology and Therapeutics, 45, 220-225. http://dx.doi.org/10.1038/clpt.1989.21

[4] Campbell, R.R.A., Hasinoff, B., Chemenko, G., Barrowman, J. and Campbell, N.R.C. (1990) The Effect of Ferrous Sulfate and $\mathrm{pH}$ on 1-Dopa Absorption. Canadian Journal of Physiology and Pharmacology, 68, 603-607. http://dx.doi.org/10.1139/y90-087

[5] Campbell, N.R.C., Ranfine, D., Goodridge, A.E., Hasinoff, B.B. and Kara, M. (1990) Sinemet-Ferrous Sulphate Interaction in Patients with Parkinson's Disease. British Journal of Clinical Pharmacology, 30, 599-605. http://dx.doi.org/10.1111/j.1365-2125.1990.tb03819.x

[6] Polk, R.E., Healy, D.P., Sahai, J., Drwal, L. and Racht, E. (1989) Effect of Ferrous Sulfate and Multivitamins with 
Zinc on Absorption of Ciprofloxacin in Normal Volunteers. Antimicrobial Agents and Chemotherapy, 33, 1841-1844. http://dx.doi.org/10.1128/AAC.33.11.1841

[7] Campbell, N.R.C., Paddock, V. and Sundaram, R. (1988) Alteration of Methyldopa Absorption, Metabolism and Blood Pressure Control Caused by Ferrous Sulfate and Ferrous Gluconate. Clinical Pharmacology and Therapeutics, 43, 381386. http://dx.doi.org/10.1038/clpt.1988.47

[8] Campbell, N.R.C., Hasinoff, B. and Campbell, R.R.A. (1990) Ferrous Sulfate Reduces Methyldopa Absorption: Methyldopairon Complex Formation as a Likely Mechanism. Clinical and Investigative Medicine, 13, 329-332.

[9] Hoffman, B.B., Lefkowitz, R.J., Gilman, A.G., Hardman, J.G., Limbird, L.E., Molinoff, P.B. and Rudon, R.W. (1996) The Pharmacological Basis of Therapeutics. 9th Edition, MacGraw-Hill, New York.

[10] The United States Pharmacopoeial Convention, Rockville, M.D. (2000) The United States Pharmacopoeia. 24 ${ }^{\text {th }}$ Edition, The National Formulary, 19.

[11] Amin, D. (1986) Titrimetric Determination of Catecholamines and Related Compounds via Bromine Oxidation and Substitution. The Analyst, 111, 255-257. http://dx.doi.org/10.1039/an9861100255

[12] Walash, M.I., Abou-Ouf, A. and Salem, F.B. (1985) Spectrophotometric Determination of Methyldopa in Pharmaceutical Formulations. Journal of the Association of Official Analytical Chemists, 68, 91.

[13] Mohamed, W.I. and Salem, F.B. (1984) Spectrophotometrio and Titrimetric Determination of Certain Adrenergic Drugs. Analytical Letters, 17, 191-203. http://dx.doi.org/10.1080/00032718408065278

[14] Salem, F.B. (1987) Spectrophotometric and Titrimetric Determination of Catecholamines. Talanta, 34, 810-812. http://dx.doi.org/10.1016/0039-9140(87)80101-7

[15] Salem, F.B. (1993) Titrimetric and Spectrophotometric Determination of Catecholamines. Analytical Letters, 26, 19591966. http://dx.doi.org/10.1080/00032719308017443

[16] Salem, F.B. (1993) Spectrophotometric and Fluorimetric Determination of Catecholamines. Analytical Letters, 26, 281-294. http://dx.doi.org/10.1080/00032719308017385

[17] Martinez-Lozano, C., Pérez-Ruiz, T., Tomas, V. and Val, O. (1991) Determination of Epinephrine, Norepinephrine, Dopamine and L-Dopa in Pharmaceuticals by a Photokinetic Method. The Analyst, 116, 857-859. http://dx.doi.org/10.1039/an9911600857

[18] Garrido, M.E., Lima, J.L.F.C. and Delerue-Mattos, C. (1997) Flow Injection Amperometric Determination of L-Dopa, Epinephrine or Dopamine in Pharmaceutical Preparations. Journal of Pharmaceutical and Biomedical Analysis, 15, 845-849.

[19] Sharma, C., Mohanty, S., Kumar, S. and Rao, N.J. (1996) Gas Chromatographic Analysis of Chlorophenolic, Resin and Fatty Acids in Chlorination and Caustic Extraction Stage Effluent from Kahi-Grass. The Analyst, 121, 1963-1967. http://dx.doi.org/10.1039/an9962101963

[20] Lee, H.B., Hong-You, R.L. and Fowlie, P.J. (1989) Chemical Derivatization Analysis of Phenols. Part VI. Determination of Chlorinated Phenolics in Pulp and Paper Effluents. Journal of the Association of Official Analytical Chemists, 72, 979-984.

[21] Tsuchiya, H., Sato, M., Kato, H., Okubo, T., Juneja, L.R. and Kim, M. (1997) Simultaneous Determination of Catechins in Human Saliva by High-Performance Liquid Chromatography. Journal of Chromatography B: Biomedical Sciences and Applications, 703, 253-258. http://dx.doi.org/10.1016/S0378-4347(97)00412-X

[22] Parsons, L.R., Kerr, T.M. and Weiss, F. (1998) Simple Microbore High-Performance Liquid Chromatographic Method for the Determination of Dopamine and Cocaine from a Single in Vivo Brain Microdialysis Sample. Journal of Chromatography B: Biomedical Sciences and Applications, 709, 35-45. http://dx.doi.org/10.1016/S0378-4347(98)00024-3

[23] Nozaki, O., Iwaeda, T. and Kato, Y. (1996) Amines for Detection of Dopamine by Generation of Hydrogen Peroxide and Peroxyoxalate Chemiluminescence. Journal of Bioluminescence and Chemiluminescence, 11, 309-313. http://dx.doi.org/10.1002/(SICI)1099-1271(199611)11:6<309::AID-BIO424>3.0.CO;2-6

[24] Kozminski, K.D., Gutman, D.A., Davila, V., Sulzer, D. and Ewing, A.G. (1998) Voltammetric and Pharmacological Characterization of Dopamine Release from Single Exocytotic Events at Rat Pheochromocytoma (PC12) Cells. Analytical Chemistry, 70, 3123-3130. http://dx.doi.org/10.1021/ac980129f

[25] Fiaz, T., Fatima, N. and Zaidi, S.Z.A. (2013) Complexation of Iron by Dopamine Analogs: A Spectrophotometric and Potentiometric Study. Pakistan Journal of Chemistry, 3, 75-80. http://dx.doi.org/10.15228/2013.v03.i02.p06

[26] Fatima, N., Zaidi, S.Z.A., Nisar, S. and Qadri, M. (2013) pH Effect on Stoichiometry and Stability of Ferrous Complexes of (-)-3-(3,4-Dihydroxyphenyl)-L-alanine. Pakistan Journal of Chemistry, 3, 23-28. http://dx.doi.org/10.15228/2013.v03.i01.p04

[27] Zaidi, S.Z.A. and Fatima, N. (2014) A Comparative Study for Chelation of Iron(II) and Iron(III) with Levodopa-An Antiparkinsonian Drug Molecule. European Chemical Bulletin, 3, 648-653. 
[28] Lykos, P. (1992) The Beer-Lambert Law Revisited: A Development without Calculus. Journal of Chemical Education, 69, 730-732. http://dx.doi.org/10.1021/ed069p730

[29] Skoog, D.A., Holler, F.J. and Nieman, T.A. (1998) Principles of Instrumental Analysis. Saunders College Publishing, Philadelphia.

[30] Sawyer, D.T., Heineman, W.R. and Beebe, J.M. (1984) Chemistry Experimental for Instrumental Methods. John Wiley and Sons, Inc., Hoboken. 